\title{
Gamification in the wild: Faculty perspectives on gamifying learning in higher education
}

\author{
Aaron Chia Yuan Hung, Emilia Zarco, \\ Monica Yang, Diane Dembicki, Mitchell Kase \\ Adelphi University
}

\begin{abstract}
While numerous studies have examined gamification from the students' perspectives, few studies focus on the faculty's experience in detail. This article analyzes the experiences and self-reflections of five university instructors/coresearchers who designed and implemented gamification for their online or hybrid courses. The study uses design-based research to formulate and test the gamification design, and draws on Google Hangout videos collected from weekly meetings between the instructors, as well as meeting minutes, design documents, emails, and informal reflections that retrospectively examine the process of gamifying the courses. The instructors acknowledge that creating a coherent gamified course was difficult and time-consuming. However, the process of designing itself may be worth reviewing because it made faculty more conscious of how their teaching values were being reflected in the gamified system. The article ends with reflections on the institutional and technological constraints that were encountered, and it offers recommendations on how to support educators new to gamifying learning in their courses.
\end{abstract}

Keywords: gamification; learning management systems; online learning; Moodle; badges

Gamification, defined as "the use of game design elements in non-game contexts" (Deterding, Dixon, Khaled, \& Nacke, 2011, p. 10), has been used for commercial purposes to retain consumers and improve brand awareness (Zichermann \& Cunningham, 2011). In education, the gamification of learning promises to help motivate students by improving their engagement, providing more immediate feedback, increasing student choice, supporting learning communities, and fostering collaboration (Kapp, 2012; Lee \& Hammer, 2011; Nicholson, 2013; 2015). Furthermore, gamification is intended to make learning and teaching more fun and meaningful for both instructors and students through features such as challenges, quests, competitions, narratives, and avatars (Kapp, 2012; Landers \& Landers, 2014; Nicholson, 2015).

To date, most studies of gamification in higher education have examined student perspectives and learning outcomes, focusing on measures such as changes in grades/ achievement (Domínguez et al., 2013; Yildirim, 2017), motivation (Buckley \& Doyle, 2016; Hanus \& Fox, 2015; Lister, 2015; Mitchell, Danino \& May, 2013), participation/attendance 
(Barata, Gama, Jorge, \& Gonçalves, 2013; Caton \& Greenhill, 2014; O’Donovan, Gain, Marais, Donovan, \& Marais, 2013), and overall impressions of the gamification system (Berkling \& Thomas, 2013; de Byl, 2013; Haaranen, Ihantola, Hakulinen, \& Korhonen, 2014; Nicholson, 2012). In addition, most of these studies have been implemented in fields such as computer science, information technology, game design or engineering (Dicheva, Dichev, Agre, \& Angelova, 2015; Nah, Zeng, Telaprolu, Ayyappa, \& Eschenbrenner, 2014; Sheldon, 2011), where instructors and students are likely to be more familiar with games, game design, and systems thinking. One question that is seldom explicitly addressed is: How do faculty respond to the process of conceptualizing and implementing gamified learning?

To address this question, we used design-based research to formulate a study to examine how we, as instructors and co-researchers, might use gamification in an existing online or hybrid course. Since we taught in a variety of fields, including nursing, health studies, business, and educational technology, we wanted to see if gamification can be meaningfully used in disciplines outside of conventional fields in which gamification are typically implemented. Most of us were familiar with common forms of gamification, such as customer loyalty points and frequent flier miles; some had deeper exposure through video games and other gamified applications, such as Foursquare. Finally, we also wanted to examine local institutional and technological constraints of implementing gamification, since these are seldom explicitly studied in detail, even though they are integral to any educational innovation.

Our decision to investigate gamification was driven by the growing trend at our university, and higher education in general, toward offering more courses and programs in online and hybrid modalities as a way of giving students more flexibility in their schedules and learning preferences. However, the challenges of adapting a traditional, face-toface course to a fully online or hybrid mode, and transforming it into a robust learning environment has been well-documented (Czerkawski, 2014; Ray, 2009; Shea, 2007; Wingo, Ivankova, \& Moss, 2017). As such, our broader goals for this project were to investigate whether gamification can be used to improve instructional design in a way that could appeal to and benefit both students and faculty.

\section{Literature Review}

Gamification in education encompasses a wide range of tools and approaches that are typically presented as an overlay of added incentives designed to give students guidance on their progression through the class. Features such as badges, achievements, and levels provide students with a roadmap to success by showing them where they stand and how they can/should proceed. Gamification can also signify to students what values and skills are important to the class, and give instructors an extra set of tools, in addition to traditional grading, to use to motivate and offer feedback. Quests, narratives, virtual currency, and avatars draw inspiration from role-playing games, and allow instructors to design courses with mini-narratives that students, as players, can pursue (Sheldon, 
2011). Other forms of gamification overlap with good instructional design, such as giving students multiple pathways to learning and showing competence (Nicholson, 2013) and freedom to take risks without fear of failing (Lee \& Hammer, 2011).

Empirical studies of gamified courses generally show mixed (Berkling \& Thomas, 2013; Domínguez et al., 2013; Haaranen et al., 2014) to positive (Barata et al., 2013, Dicheva et al., 2015; Nah et al., 2014; Wiggins, 2016) results. However, it can be hard to make practical use of these studies because of the variety of contexts and ways in which gamification can be designed and implemented (Hung, 2017). Furthermore, the tendency for these studies to focus only on students' perspectives means that there is a gap in research with regard to how the faculty perceive the process of gamification. We speculate two possible reasons for this gap. First, since many gamification studies are published in computer or technology-focused journals and conference proceedings, and conducted by researchers with game design and/or computer science backgrounds, their familiarity with game elements and design principles may have led them to emphasize more on students than on their own design rationale and process. Second, the strive for objectivity may have resulted in less focus on reflective practice in favor of outcomes such as student grades, attendance, and survey data.

In our view, faculty reflections are crucial because designing the gamified system and implementing it consistently is a time-consuming and burdensome task that they must do in addition to regular instruction. Furthermore, metacognitive reflection is important not only for students but also for teachers and other professionals (Bransford, Brown, \& Cocking, 2000; Schön, 1987). Schön (1984) suggests that reflection-in-action by practitioners can reveal how they confront emergent problems and how they map a course of action to resolve such problems. These reflections are important because, although every problem that practitioners face is unique, having the opportunity to see others reflect on their process can be a useful resource. In the few studies that include the instructor's reflections, we see the everyday realities of what it is like to implement gamification. For instance, while reflecting on his experience of gamifying two higher education courses, Nicholson (2013) observes that his use of optional assignments as a way of providing students with more options may not have been successful because this was a required course. He notes that some students may not have had intrinsic interest in this course, and, consequently, did not buy into the gamified elements. He also notes that, by trying to give students more agency, his approach may have relied too much on students being self-driven learners, while not giving weak students enough encouragement.

\section{Methodology}

Reflections such as Nicholson's are helpful because it exposes possible unintended consequences of a gamified system that may not be self-evident from the design. Reflection is also a part of design-based research (Barab \& Kirshner, 2001; Barab \& Squire, 2004; Reeves, Herrington \& Oliver, 2005; The Design-Based Research Collective, 
2003; Wang \& Hannafin, 2005), which is the approach we used to inform our gamification design and implementation decisions.

A key goal of design-based research is to study innovative learning in real world contexts and to improve the implementation through multiple iterations. Unlike controlled, experimental research, design-based research is characterized by its embrace of real world complexities, multiple and changing variables, flexible design revisions, and involvement of multiple co-participants (Barab \& Kirshner, 2001; Barab \& Squire, 2004; Collins, 1999; Collins, Joseph, \& Bielaczyc, 2004). In addition, Barab and Kirshner (2001) argue that one of the goals of using design-based research is "to employ research methodologies that allow us to describe local challenges and develop local instructional theories in a manner that supports others in adapting lessons learned in one context to their local contingencies" (p. 12). For us, that meant investigating challenges that may be unique to our disciplines and courses, as well as to our institutional context and learning management system (LMS), and identifying ways in which these challenges can be addressed in future iterations in other courses and/or by other faculty.

\section{Participants}

In design-based research, the researcher takes on multiple roles, including that of the instructor. Since one focus of our study is the faculty perspective of gamification, the authors are also the core participants. Aaron teaches in the educational technology program. The two courses he used for this study were both fully online courses. Emilia is an associate professor in health studies program and the course she used for this study was a hybrid course. Monica is an associate professor in the School of Business. She taught one undergraduate and one graduate course, both of which were hybrid courses. Diane is a clinical associate professor in nutrition who was interested in using gamification for their new fully online program, and piloted it in a fully online course for this study. Finally, Mitch is an adjunct professor and a part of the university's faculty support center. Aaron and Mitch are familiar with gamification through video games and both piloted badges in Phase I (discussed below) of the study.

\section{Data collection}

Our data consists primarily of weekly meetings recorded over Google Hangout, as well as meeting minutes, design documents, emails, and informal reflections after the gamified courses have ended. This retrospective analysis of the design process aligns with Wang and Hannafin's (2005) two-level coding: one level involves data from ongoing observations, and another level involves a distillation of those observations into design principles. Since we were on campus at different times, we typically held our weekly meetings on Google Hangout, which were recorded and archived. We encouraged one another to share not only success stories but also frustrations as they emerged. We also shared our brainstorming notes and badge designs so that we could see what others in the group were doing. Since we had different implementation timelines, it was helpful for those who were deploying gamification in a later semester to know about the experiences of those who went earlier. 


\section{Our approach to gamification}

Instead of employing a one-size-fit-all approach, we felt it was important to consider the different learning outcomes of the courses and dispositions of students as part of our planning. This led to some variation in how we approached key mechanics, such as competition. Most of us started with badges, which was part of our institution's latest Moodle version upgrade. We spent the summer testing the mechanics and learning how badges work. Regular students' responses were also part of the feedback loop that helped inform continuing refinement.

Although gamification is often tied to assignments and grades (Barata et al., 2013; de Byl, 2013; Sheldon, 2011), we wanted to avoid that for the following reasons:

- Since students already receive points and/or grades as a regular part of class, we felt that having a gamification system that is too closely tied to grades would be redundant. Instead of duplicating the grading system, we wanted gamification to complement it by focusing on aspects of the student's learning that are difficult to quantify with a grade.

- Formal grading often focuses on demonstrations of academic skill and knowledge. However, Rosenbaum (2001) argues that employers often value dispositions and noncognitive behaviors such as attendance, dependability, effort, problem solving, leadership, collaborative skills and punctuality more than academic skills and content knowledge. These noncognitive behaviors are not easy to quantify but are ideal for gamification to address.

- We wanted gamification to be an optional feature of the course (Domínguez et al., 2013). Gamification in other contexts, such as Foursquare, Xbox Gamerscore, PlayStation Trophies, and so on, are added features that users can choose to pursue or ignore. Furthermore, since some of us were new to gamification, we did not want our newness to impact students' grades unfairly.

- We felt that having gamification too closely tied to grades and assignments would make it difficult to disentangle whether students were motivated by gamification or by the desire to attain a good grade.

At the beginning of the course, students were told, either through a text or video message displayed on Moodle, that the course they were taking would involve gamified elements. They were given a brief explanation of what gamification was and were told that they were all eligible to receive badges but were not required to actively pursue it. They were also given a survey that asked about their experiences with online learning, background knowledge on gamification, and what kinds of classroom dynamics they valued as students. By classroom dynamics, we meant interactions, environments, or experiences such as "Feeling challenged by the topics presented," "Having choice in how to learn," "Having choice in how to demonstrate my competency," and so on. These classroom 
dynamics were drawn from studies of rich learning environments (Bransford et al., 2000), which we aimed to foster through gamification. We also asked what kinds of classroom dynamics could be addressed or improved by gamification. Table 1 shows the number of students involved in each course, how the course was delivered, and whether they were undergraduate or graduate students.

Table 1.

Number of participating students, discipline, mode of delivery, and educational level

\begin{tabular}{|l|c|l|l|}
\hline \multicolumn{1}{|c|}{ Discipline } & $\begin{array}{c}\text { Number of } \\
\text { students }\end{array}$ & \multicolumn{1}{|c|}{$\begin{array}{c}\text { Mode of } \\
\text { delivery }\end{array}$} & \multicolumn{1}{|c|}{ Educational level } \\
\hline $\begin{array}{l}\text { Educational Technology } \\
\text { (Philosophy) }\end{array}$ & 7 & Hybrid & Graduate \\
\hline $\begin{array}{l}\text { Educational Technology (Social } \\
\text { Media) }\end{array}$ & 22 & Online & Graduate \\
\hline $\begin{array}{l}\text { Nursing and Public Health } \\
\text { (Nutrition) }\end{array}$ & 11 & Online & Graduate \\
\hline Business & 43 & Online & $\begin{array}{l}\text { Undergraduate / } \\
\text { Graduate }\end{array}$ \\
\hline Health Studies & 60 & Online & Undergraduate \\
\hline
\end{tabular}

Parts of our designs were constrained by how badges were implemented in Moodle. There are two main ways to assign badges on Moodle. They can be assigned manually by someone in a particular role, usually the teacher, unless additional roles are created and specified. They can also be automatically awarded when certain conditions are met; for example, they can be given if the student receives a passing grade on an assignment or quiz, or if they meet additional criteria set by the instructor, such as requiring students to post a certain number of discussion responses in forums. These criteria are tied to variables that are easy for the Moodle to track and measure, such as dates, grades, and number of posts. The limitation is that Moodle can only track quantifiable measures, such as when a student posts something to the forum, but it cannot measure how thoughtful or well written the post is. For that reason, we decided to use automated badges sparingly, and we designed most of our badges to be manually assigned.

\section{Results}

\section{Phase I - Initial design}

Some of us did a soft launch of our badges in the fall semester with two online courses as a way of understanding how the badges worked and which game mechanics should be added, modified or abandoned. We quickly learned that having too many badges became difficult to manage over the duration of the courses, particularly if they were to be manually assigned. We also realized that, while hidden badges are common in many 
gamified applications, they are less useful in a learning environment, as other studies have also noted (Haaranen et al., 2014).

In our weekly meetings, three major themes surfaced. The first theme had to do with how gamification made us more thoughtful and reflective in the way we were using it in our courses, making sure that they were aligned to the types of motivation we wanted to encourage as well as to the overall learning goals. For example, one faculty noted:

That's why I like the idea that it's not in the grading. We are removing that pressure of grade. I didn't want the badge to be another pressure for [the students] to do well on just those things that were being graded. I would really like them to focus more on skills that they would like to develop to be successful.

Following that remark, another faculty, talking about deciding who should receive a 'Best Comment of the Week' badge, observed:

I noticed that my own behavior has started to change because of badges... Last week, I was trying to decide between [awarding the badge to] this really shy student - and this was on VoiceThread - who didn't want to do a VoiceThread voice recording. I encouraged her, and she did [the recording,] and it was pretty good. Another student had a really good comment too, and I was trying to decide which student I should award [the badge] to. It was really interesting to have to think about that.

'Change in teaching' was a common theme in our reflections, as the process of gamifying a course made many of us more aware of what teaching values were manifesting in the class. In the course of designing badges, and through conversations with other faculty members, some of us also became more thoughtful about how a badge should be valued within the course. For example, one faculty reflected on how badges should not be too easy to acquire, and that it should be something students have to strive for:

I like the badges as motivational objects in the course. l've been toying around with: Do I want to have someone [get] a badge for posting [a forum response] first, or for the most substantial tweet of the week? I'm still looking at those. Just setting up your account on Twitter and tweeting everyday isn't enough. l'd like to have a more dynamic use of [badges]. I'm also trying to see if I can use badges to get students to collaborate with each other more.

In short, these discussions were ways for us to surface our own teaching philosophies and explore whether these philosophies can be mapped coherently onto a gamified system.

The second theme to emerge was our struggle over whether badges would create a sense of competition that would be antithetical or distracting to learning. One faculty 
wanted to use badges to create a more supportive environment by having badges promote activities that students are encouraged, but not required, to do:

The last two weeks l've been really thinking a lot and changing my ideas of what I'm going to do...I was thinking, one aspect for collaboration, [the students] are required to respond to what I post for the discussion forums. They do have the opportunity to comment on other students' comments. They don't always do that, and I thought, perhaps giving a badge when they do comment in a supportive way.

Knowing the students' personalities and dispositions was an important part of deciding whether students would respond positively to a more or less competitive environment. Initially, there were some who were worried that gamification was inherently competitive. One faculty voiced:

I'm really concerned about the competition thing, and l'd like to remove that. I was wondering, instead of having badges displayed to everyone in the class, could it just be displayed to the students earning them? I know, already, the personalities of the students in this class. I know a couple of them are going to be turned off by any competition. It kinda looks like pseudo-grading, and l'd like to get away from that.

In our version of Moodle, all badges were visible on the student's profile. However, based on the students' focus group responses and our observations gathered from the learning analytics, students did not usually visit one another's profiles. As such, badges were buried in the LMS interface even though they were technically accessible. Furthermore, not every faculty had the same concern about competition. Another faculty pointed out that grades already create a competitive environment, and argued that students who were inherently more competitive would be competitive with badges, too:

In a class, they're really competing with each other. If your personality is competitive, you're really bound to compete if you see others getting more. It's an integral part of the process. As long as we don't position [badges] as a competition, I think that's okay.

The concern about badges being competitive was somewhat alleviated by discussions on how to create a less competitive ecosystem of badges. For example, an ecosystem that focuses on scarcity by limiting badges to one per student would be more competitive than one where badges were not limited in such a way.

The third theme that emerged was a reflection on the value of discussing learning and teaching in relation to gamification. The discussion of badges, and gamification in general, made abstract values more concrete. This had the effect of making us question whether something was worthy of being made into a badge. Furthermore, it was often difficult for faculty, especially across departments and colleges, to regularly share ideas about teaching practices and pedagogy. These gamification meetings created a space 
that allowed us to voice our values, challenge one another in an open forum, and reflect on our teaching styles. One faculty summarized it by saying:

I think it's wonderful all the discussions we're having and how this project is making us rethink our teaching and learning. I think that is a great benefit to all of us, and ultimately, our students.

\section{Phase II - Revised design}

Based on our Phase I experiences in the fall, we revised our badges for the spring semester. Each course had roughly six to eight badges. Table 2 lists some examples of the badges that were used. Since each instructor taught a different discipline, it was up to each of us to design and implement the form of gamification that was most suited to our courses and field of study.

Table 2.

Sample badges, disciplines and conditions

\begin{tabular}{|l|l|l|}
\hline \multicolumn{1}{|c|}{ Badge Name } & \multicolumn{1}{|c|}{ Discipline } & \multicolumn{1}{c|}{ Condition } \\
\hline Syllabus Expert & $\begin{array}{l}\text { Educational } \\
\text { Technology } \\
\text { (Philosophy) }\end{array}$ & $\begin{array}{l}\text { Automatically awarded when students complete an } \\
\text { ungraded quiz to demonstrate they have read the } \\
\text { syllabus }\end{array}$ \\
\hline $\begin{array}{l}\text { Social Media } \\
\text { Expert }\end{array}$ & $\begin{array}{l}\text { Educational } \\
\text { Technology } \\
\text { (Social Media) }\end{array}$ & $\begin{array}{l}\text { Manually awarded to student who shows proficiency in } \\
\text { managing her social media site assignment }\end{array}$ \\
\hline $\begin{array}{l}\text { Clear Thinking } \\
\text { and Writing }\end{array}$ & $\begin{array}{l}\text { Nursing and } \\
\text { Public Health }\end{array}$ & $\begin{array}{l}\text { Manually awarded to the student who shows excellence } \\
\text { in writing and expression }\end{array}$ \\
\hline $\begin{array}{l}\text { Creative Problem } \\
\text { Solving }\end{array}$ & $\begin{array}{l}\text { Nursing and } \\
\text { Public Health }\end{array}$ & $\begin{array}{l}\text { Manually awarded to student who is able to creatively } \\
\text { solve a problem associated with an assignment }\end{array}$ \\
\hline $\begin{array}{l}\text { Persuasive } \\
\text { Comment of the } \\
\text { Week }\end{array}$ & Business & $\begin{array}{l}\text { Manually awarded to students who satisfy all } \\
\text { requirements on discussion forum activities and makes } \\
\text { the most persuasive argument }\end{array}$ \\
\hline $\begin{array}{l}\text { Communication } \\
\text { and Critical } \\
\text { Thinking }\end{array}$ & Business & $\begin{array}{l}\text { When a student receives the Persuasive comment of the } \\
\text { week badge at least three times over whole semester, } \\
\text { this badge is awarded manually at the end of semester. }\end{array}$ \\
\hline Life Skill: Fitness & $\begin{array}{l}\text { Health } \\
\text { Studies }\end{array}$ & $\begin{array}{l}\text { Manually awarded to student who achieves the personal } \\
\text { fitness goals he/she has set for himself/herself }\end{array}$ \\
\hline Life Skill: Sleep & $\begin{array}{l}\text { Health } \\
\text { Studies }\end{array}$ & $\begin{array}{l}\text { Manually awarded to student who achieves the personal } \\
\text { sleep goals he/she has set for himself/herself }\end{array}$ \\
\hline $\begin{array}{l}\text { Life Skill: Healthy } \\
\text { Eating }\end{array}$ & $\begin{array}{l}\text { Manually awarded to student who achieves the personal } \\
\text { healthy eating goals he/she has set for himself/herself }\end{array}$ \\
\hline
\end{tabular}

After all of us had implemented gamification in our courses, we had a final reflection on our experiences on gamification in general, as well as the challenges and opportunities 
for future iterations. With regard to benefits, one faculty reflected:

I learned something about gamification - specifically digital badges. I became very interested in applying the little knowledge I learned about them, and I am still interested in continuing to learn more how to use this in a class and how it truly impacts student learning. It was interesting to note that most of my students are not familiar with digital badges at all. But they were interested to make it as part of their learning experience. I learned that gamifying a course demands a comprehensive plan which involves thinking through the course objectives and topics to be able to identify which student outcomes will be awarded with badges. I also found several resources to help someone start. However, I felt that very few faculty aside from us are interested in using digital badges despite its potential to impact learning and performance.

Another faculty noted how it was important for gamification to be aligned to learning objectives in a way that would make students understand how to succeed in the course:

The process truly required a close examination of learning objectives and refining assessments. I felt like the more successful activities were closely tied to objectives that were easily measured. It also encouraged me to provide very clear criteria for the gamified activities which definitely helped students produce more successful artifacts. Overall, the greatest benefit from my perspective was careful consideration of each aspect of the course and realigning them with learning objectives or revising objectives as necessary.

As mentioned earlier, our primary goal in using gamification was to motivate students to become better learners and thinkers. As such, we minimized tying the gamified elements to aspects of student participation that could be easily tracked and automated by Moodle because we felt this would trivialize or oversimplify our intended goals. This shifted the burden of awarding badges to the instructor. As part of our reflection, we wanted to see if this added burden was worth the effort, whether it could be sustainably implemented in the rest of our courses, and how it can be improved.

\section{Future directions for gamification}

The remainder of this article summarizes our perspectives on how to improve gamification in the future. We discuss the challenges and opportunities for gamification at our institution. The three challenges we focus on pertain to understanding gamification as a concept, sustaining gamification over the duration of the course, and confronting technical challenges in Moodle. We also discuss challenges in relation to institutional and technological constraints, especially as they relate to how badges are implemented in Moodle. We follow that with a discussion of the opportunities that gamification opened up for us, specifically gaining meta-awareness of our teaching approaches and values and considering future improvements of our gamified designs for future courses. 


\section{Challenges}

Gamification can be a difficult concept for non-gamers to grasp because they can be easily confused with other game-related approaches, such as game-based learning, serious games, and games for learning. The commonly cited definition by Deterding et al (2011), who describe gamification as "the use of game design elements in non-game context" (p. 10) is a good starting point, but this definition becomes blurry when applied to a classroom context.

First, classrooms are already "gamified" environments. Most formal classrooms use points and/or letter grades, have time constraints, and limit resources in some contexts, such as during quizzes and exams. Some of us already incorporate teaching practices, such as giving students the freedom to fail at a task, personalizing learning, and display of learning gains (Hung, 2017), all of which are considered forms of gamification (Dicheva et al., 2015). Second, gamification can easily be confused with entertainment games, serious games, and game-based learning, since they tend to also contain their own forms of gamification, such as trophies and achievements (Hamari \& Eranti, 2011). Many entertainment games also 'grade' players' performance using points and letter grades. For game scholars, entertainment games, game-based learning and gamification may seem to be distinct categories, despite their considerable overlap, but for non-gamers, these distinctions are less clear. As such, we wanted to explore gamification in a way that avoids creating a system that simply rewards positive behavior, but also sets up a meaningful form of interaction for students. Third, the vagueness and broadness of gamification as an educational innovation makes it difficult to easily grasp as a concept, especially for newcomers, and it was often a challenge to explain it to students. One faculty observed that:

When I talk to people about badges outside our group, they have no idea what I'm talking about...Explaining [badges] [to students], scaffolding the process of acquiring a badge is really going to be helpful... The closest thing to this is really the Boy Scouts or Girl Scouts. When you talk about that, they instantly get the visual and go 'Oh okay, now I know what you're talking about.'

Moodle itself created a lot of challenges for implementing badges. First, the overall interface of the Moodle version we were using at the time (i.e., version 2.7) was not particularly user-friendly. Features such as quizzes, activity completion, restrictions, tracking, log reports, and badge design itself were cumbersome to use. For instance, to create a badge, instructors had to determine the badge's name, description, image file, expiration date, message to be sent to recipient, and criteria (which is itself a multistep process). Although Moodle allows instructors to set up complex, nested sets of conditions for automated badges, this was only useful if the course can unfold in a predictable manner. Since we tried to adapt courses to fit students' needs, it was not always easy to predict how a course would go, making it a challenge to design complex automated badges ahead of time. 
Furthermore, badges were not centrally featured in the user interface. While we were able to add a "badges earned" block to showcase the latest badges that a student earned more prominently, this block only displayed what the student logged in has achieved, and not what the rest of the class had achieved. The only way to navigate to what other students have earned was through the class participant profile page, which most students (according to the learning analytics) did not visit. As such, it was hard to foster a meaningfully competitive environment where students would strive for badges that their classmates earned.

\section{Opportunities}

One of the most valuable parts of our experience with gamification was the way the discussions between the instructors involved brought about a meta-awareness of how we approached teaching and learning. To design the badge ecosystem, we had to reflect on what we considered to be valuable skills, experiences and knowledge for our students to acquire. We also considered ways in which gamification, and online classes in general, can break out of traditional, linear teaching models and offer complex pathways, self-guided learning, and personalized instruction with gamification as the guiding mechanism for students. For example, one faculty noted, "I am just realizing how much traditional teaching still constrains my thinking, and l'd love to imagine a syllabus in which it's not unnecessarily boxed in by these boundaries. I think gamification is a piece of this puzzle." While our gamified learning designs have yet to achieve that vision, we saw (and still consider) gamification as a productive exercise to reconceptualize the way we teach.

Gamification also made parts of our instruction and educational values more transparent to the students and ourselves. Since we had to manually assign the badges, it was necessary to be conscious about what it meant for a student to demonstrate a particular competency or deserve a "Best Comment of the Week" badge. Although the use of spreadsheets to track badges was cumbersome, it became a worthy exercise when it came to pondering who deserved a badge. Since badges were disassociated from grades, the process of assigning badges was also decoupled with concerns about its impact on GPA. Finally, some of us also felt that gamification gave us a new creative outlet. Having fun is one of the goals of gamification, both for students and faculty. In short, we felt that badges gave us a different and useful lens through which to consider our instruction by making us more aware of what we should value in our classrooms.

\section{Implications for future designs}

\section{Third-party applications}

In our initial approach to gamification, we avoided using third-party applications because we wanted more control over how gamification would affect our courses. Many thirdparty applications, such as PeerWise (peerwise.cs.auckland.ac.nz) and Classcraft (www. classcraft.com), have built-in gamification features that can be used with or parallel to 
an existing LMS. Classcraft, for example, is presented as a fantasy role-playing game (RPG), where students start the class by picking a pre-designed character with unique strengths and weaknesses to be determined by the instructor. These characters work best as a team and can earn or lose different kinds of experience points over the semester. However, third-party applications have their learning curves and are an additional application that both students and instructors have to learn to use. Furthermore, many third-party applications are not integrated into Moodle, so instructors either have to run the course on two applications or migrate to a gamified platform and re-design their coursework there. Since third-party applications are not always officially supported by the institution, instructors would also have to resolve potential problems outside the university's support system.

Third-party applications come with their own benefits and drawbacks. An application designed with gamification in mind will feature gamified elements more prominently in the course and make the integration with the coursework more meaningful. These applications may provide instructors with pre-designed elements or systems that can be adapted by specific courses. The downside is that it takes away control from both students and instructors. Students taking courses designed on Classcraft, for example, will have to accept the RPG structure, regardless of whether they are fans of the genre or if this fits their preferred method of learning. Although third-party applications usually let instructors make some adjustments to the gamification elements, these are often limited to varying point values or rewards.

\section{Enhancements to Moodle}

Although many of the obstacles we faced were inherent in Moodle, we were mindful that Moodle was used by the entire institution and cannot be easily upgraded just to fit our needs. There were also security and stability concerns that those who support the platform have to consider. Our goal is to continue testing badges and other forms of gamification and to send regular feedback to the Moodle support team. Since Moodle is open-sourced and widely used, there is a large community of users who have designed plug-ins to improve how gamification works. Its open source nature also makes it possible for administrators and technical support teams to go in and add or modify parts of the code to improve the way gamification works. However, since these changes impact the entire institution, they have to be carefully tested. We also hope to collaborate with faculty with a programming background, who can design scripts to analyze log files in Moodle, as Barata et al. (2013) were able to do in their work. These scripts will automate processes that are difficult and time-consuming for instructors to analyze manually.

\section{Student-initiated badges and certificates}

Another re-design that could alleviate the burden on instructors is to include badges as part of a student portfolio or demonstration of competency. In Diana Joseph's design research on the passion school, she created a certification system, based on the Scout merit badge system, that let students demonstrate their mastery of different expertise related to video production by completing a set of activities (Collins et al., 2004). Successful 
students are awarded a certificate and given certain rights and responsibilities, such as the ability to use the camera outside of the school building.

Similarly, a badge or certification system could work in some of our classes, especially those in educational technology, as students tend to come with varying levels of experience in programming, graphic design, creative writing, video production, and app development. Students who assemble a portfolio to demonstrate their expertise in different areas can acquire a badge and move on to advanced levels. Students can also submit an application for a badge in leadership, collaboration, or other noncognitive behaviors (Rosenbaum, 2001) that prospective employers value and feature these on their Linkedln profiles. By having students initiate these badges and certificates, instructors can focus on assessing students on a case-by-case basis, instead of monitoring the entire class.

\section{Limitations}

One limitation of this study is that it is unique to our particular experiences, disciplines, experiences with gamification, and institutional context. This means that our reflections cannot be generalized to other instructors who face different constraints and variables. Since we are both researchers and participants in the study, we have to acknowledge the potential bias that may arise. This is a challenge of conducting design-based research in general, because researchers are always an integral part of the data. We have tried to mitigate potential bias by focusing on our experiences of conceptualizing and implementing gamification, not the success or failure of the gamification itself. Another limitation is our focus on badges. This decision was based on the convenience that badges were readily integrated into Moodle, and, even though we often found it tedious to use, it was still easier than creating a new tool or platform. By the end of the study, most of us were still interested in using gamification as a tool to diagnose and reflect on our teaching, but we were not committed to limiting ourselves to badges in the future.

\section{Directions for Further Research}

One area that needs more research is the role that students' learning preferences play in how they respond to different gamification elements, and gamification in general. In describing virtual worlds, Bartle (2004) classifies users into four primary categories: some prefer to socialize; some prefer to be play offense; some enjoy individual exploration; and some like to go after challenges. He argues that designers can influence the makeup of these users by adding, removing, or modifying dynamics or features, such as encouraging socialization by adding collaborative tasks or fostering exploration by building large, open worlds.

Barata, Gama, Jorge, and Gonçalves's (2014) description of "student types" and their different responses to gamification builds on a similar idea. From our study, we observed that there are variations in how students from different disciplines prefer to learn, for 
example, with more business students indicating that they like being challenged. However, these preferences could still vary from cohort to cohort, even within the same discipline. Once an instructor understands how different students prefer to learn, she can design a gamification ecosystem that would fit best with the students' preferences. For example, if a class shows preference for a more competitive, team-based learning environment, the instructor can instill a gamification system that features more teambased, competitive activities. Over time, an instructor will develop enough configurations of gamified ecosystems that she could easily adapt them to different learner cohorts without having to re-design every enactment from scratch. Instructors can also borrow from other instructors' designs, as we did in our collaboration, to further diversify and expand gamification possibilities.

\section{Conclusion}

For this study, we focused on faculty perspectives and examined the process of conceptualizing and implementing gamification. Our retrospective analysis of our meetings and design notes revealed to us that the process of gamification itself was valuable. First, by avoiding replication or over-reliance on conventional grading, some of us could view the course in new ways. This, in turn, made us more aware of our own values on teaching and learning, and what we wanted to highlight through badges. The playful and low-stakes nature of gamification also provided more flexibility in deciding what values to emphasize. Second, the process generated important conversations about using competition as a motivating factor. Since gamification was presented as an optional layer, students could easily opt out. Finally, by having these conversations, we could talk about teaching and learning in ways that are often rare during the busy academic year. Although we may not be experts in one another's disciplines, gamification gave us a shared vocabulary for mutual understanding.

Gamification takes time to design and implement (Dominguez et al., 2013). As an educational innovation, it has a significant learning curve, both conceptually and technically. For gamification to have more widespread appeal in higher education, it needs to involve disciplines that are not traditionally represented in gamification research. By focusing on the faculty's perspectives of gamification, we aimed to anchor the practical work and concerns of gamification in particular institutional and technical realities. Although our contexts may be unique to us, all faculty who use gamification have to face analogous constraints imposed by their expertise, their access to available resources and personnel, and technological affordances. By sharing our perspectives, we hope to engage others who are interested in gamification in a conversation that extends the dialogue of using gamification in higher education beyond the focus on students to include faculty experiences as well. 


\section{References}

Barab, S. A., \& Kirshner, D. (2001). Guest editors' introduction: Rethinking methodology in the learning sciences. Journal of the Learning Sciences, 10(1-2), 5-15. doi:10.1207/S15327809JLS10-1-2_2.

Barab, S., \& Squire, K. (2004). Design-based research: Putting a stake in the ground. Journal of the Learning Sciences, 13(1), 1-14. doi:10.1207/s15327809jls1301_1.

Barata, G., Gama, S., Jorge, J., \& Gonçalves, D. (2013). Improving participation and learning with gamification. Proceedings of the First International Conference on Gameful Design, Research, and Applications - Gamification '13, 10-17. doi:10.1145/2583008.2583010.

Barata, G., Gama, S., Jorge, J., \& Gonçalves, D. (2014). Identifying student types in a gamified learning experience. International Journal of Game-Based Learning, 4(4), 19-36. doi:10.4018/ijgbl.2014100102

Bartle, R. A. (2004). Designing virtual worlds. Indianapolis: New Riders.

Berkling, K., \& Thomas, C. (2013). Gamification of a software engineering course and a detailed analysis of the factors that lead to its failure. In M. E. Auer (Ed.), Proceedings of International Conference on Interactive Collaborative Learning (pp. 525-530). Piscataway, NJ: IEEE.

Bransford, J., Brown, A. L., \& Cocking, R. R. (2000). How people learn: Brain, mind, experience, and school. Washington, DC: National Academy Press.

Buckley, P., \& Doyle, E. (2016). Gamification and student motivation. Interactive Learning Environments, 24(6), 1162-1175. doi:10.1080/10494820.2014.964263.

Caton, H., \& Greenhill, D. (2014). Rewards and penalties: A gamification approach for increasing attendance and engagement in an undergraduate computing module. International Journal of Game-Based Learning, 4(3), 1-12. doi: 10.4018/ ijgbl.2014070101.

Collins, A. (1999). The changing infrastructure of education. In E. C. Lagemann \& L. S. Shulman (Eds.), Issues in education research: Problems and possibilities (pp. 289-298). San Francisco: Jossey-Bass.

Collins, A., Joseph, D., \& Bielaczyc, K. (2004). Design Research: Theoretical and Methodological Issues. Journal of the Learning Sciences, 13(1), 15-42. doi:10.1207/s15327809jls1301_2. 
Czerkawski, B. C. (2014). Designing deeper learning experiences for online instruction. Journal of Interactive Online Learning, 13(2), 29-40. Retrieved from http://www. ncolr.org/jiol/issues/pdf/13.2.1.pdf

de Byl, P. (2013). Factors at play in tertiary curriculum gamification. International Journal of Game-Based Learning, 3(2), 1-21. doi:10.4018/ijgbl.2013040101.

The Design-Based Research Collective (2003). Design-based research: An emerging paradigm for educational inquiry. Educational Researcher, 32(1), 5-8. doi:10.3102/0013189X032001005.

Deterding, S., Dixon, D., Khaled, R., \& Nacke, L. (2011). From game design elements to gamefulness: Defining "gamification." In A. Lugmayr, H. Franssila, C. Safran, \& I. Hammouda (Eds.), MindTrek 2011 (pp. 9-15). doi: 10.1145/2181037.2181040.

Dicheva, D., Dichev, C., Agre, G., \& Angelova, G. (2015). Gamification in education: A systematic mapping study. Educational Technology \& Society, 18(3), 75-88.

Domínguez, A., Saenz-de-Navarrete, J., De-Marcos, L., Fernández-Sanz, L., Pagés, C., \& Martínez-Herráiz, J.-J. (2013). Gamifying learning experiences: Practical implications and outcomes. Computers \& Education, 63, 380-392. doi:10.1016/j. compedu.2012.12.020.

Haaranen, L., Ihantola, P., Hakulinen, L., \& Korhonen, A. (2014). How (not) to introduce badges to online exercises. In Proceedings of the 45th ACM technical symposium on Computer science education (pp. 33-38). New York: ACM Press. doi:10.1145/2538862.2538921

Hamari, J., Koivisto, J., \& Sarsa, H. (2014). Does gamification work? A literature review of empirical studies on gamification. In R. Sprague et al. (Eds.), Proceedings of 47th Hawaii International Conference on System Sciences (pp. 3025-3034). doi:10.1109/HICSS.2014.649.

Hanus, M. D., \& Fox, J. (2015). Assessing the effects of gamification in the classroom: A longitudinal study on intrinsic motivation, social comparison, satisfaction, effort, and academic performance. Computers and Education, 80, 152-161. doi:10.1016/j.compedu.2014.08.019.

Hung, A. C. Y. (2017). A critique and defense of gamification. Journal of Interactive Online Learning, 15(1), 57-72.

Kapp, K. M. (2012). The gamification of learning and instruction: Game-based methods and strategies for training and education. San Francisco: John Wiley.

Landers, R. N., \& Landers, A. K. (2014). An empirical test of the theory of gamified learning: The effect of leaderboards on time-on-task and academic performance. Simulation \& Gaming, 45(6), 769-785. doi:10.1177/1046878114563662 
Lee, J. J., \& Hammer, J. (2011). Gamification in education: What, how, Why Bother? Academic Exchange Quarterly, 15(2), 1-5.

Lister, M. (2015). Gamification: The effect on student motivation and performance at the post-secondary level. Issues and Trends in Educational Technology, 3(2), 1-22. doi:10.2458/azu_itet_v3i2_Lister.

Mitchell, N., Danino, N., \& May, L. (2013). Motivation and manipulation: A gamification approach to influencing undergraduate attitudes in computing. In P. Escudeiro \& C. V. de Carvalho (Eds.), Proceedings of European Conference on Game-Based Learning (pp. 394-400). Porto, Portugal: ACPL.

Nah, F. F.-H., Zeng, Q., Telaprolu, V. R., Ayyappa, A. P., \& Eschenbrenner, B. (2014). Gamification of education: A review of literature. In F. F.-H. Nah (Ed.), Proceedings of 1st International Conference on Human-Computer Interaction in Business (pp. 401-409). Crete, Greece: LNCS Springer.

Nicholson, S. (2012, June). A user-centered theoretical framework for meaningful gamification. Paper presented at Games+Learning+Society 8.0, Madison, WI.

Nicholson, S. (2013, June). Exploring gamification techniques for classroom management. Paper presented at Games+Learning+Society 9.0, Madison, WI.

Nicholson, S. (2015). A RECIPE for meaningful gamification. In T. Reiners \& L. A. Wood (Eds.), Gamification in education and business (pp. 1-20). New York, NY: Springer.

O'Donovan, S., Gain, J., \& Marais, P. (2013). A case study in the gamification of a university-level games development course. Proceedings of South African Institute for Computer Scientists and Information Technologists Conference (pp. 245-251). doi:10.1145/2513456.2513469

Ray, J. (2009). Faculty perspective: Training and course development for the online classroom. MERLOT Journal of Online Learning and Teaching, 5(2), 263-276.

Reeves, T., Herrington, J., \& Oliver, R. (2005). Design research: A socially responsible approach to instructional technology research in higher education. Journal of Computing in Higher Education, 16(2), 96-115. doi:10.1007/BF02961476.

Robertson, M. (2010). Can’t play, won't play. Retrieved December 12, 2016, from http:// www.hideandseek.net/2010/10/06/cant-play-wont-play

Rosenbaum, J. E. (2001). Beyond college for all: Career paths for the forgotten half. New York: Russell Sage.

Schön, D. A. (1984). The reflective practitioner. New York: Basic Books. 
Schön, D. A. (1987). Educating the reflective practitioner. San Francisco: Jossey-Bass.

Shea, P. (2007). Bridges and barriers to teaching online college courses: A study of experienced online faculty in thirty- six colleges. Online Learning, 11(2), 73-128.

Sheldon, L. (2011). The multiplayer classroom: Designing coursework as a game. Boston: Cengage Learning.

Wang, F., \& Hannafin, M. J. (2005). Design-based research and technology-enhanced learning environments. Educational Technology Research and Development, 53(4), 5-23. doi:10.1007/BF02504682.

Wiggins, B. E. (2016). An overview and study on the use of games, simulations, and gamification in higher education. International Journal of Game-Based Learning, 6(1), 18-29. doi:10.4018/IJGBL.2016010102.

Wingo, N. P., Ivankova, N. V., \& Moss, J. A. (2017). Faculty perceptions about teaching online: Exploring the literature using the technology acceptance model as an organizing framework. Online Learning, 21(1), 15-35. doi:10.24059/olj.v21i1.761

Yildirim, I. (2017). The effects of gamification-based teaching practices on student achievement and students' attitudes toward lessons. The Internet and Higher Education, 33, 86-92. doi:10.1016/j.iheduc.2017.02.002.

Zichermann, G., \& Cunningham, C. (2011). Gamification by design. Sebastopol: O'Reilly. 